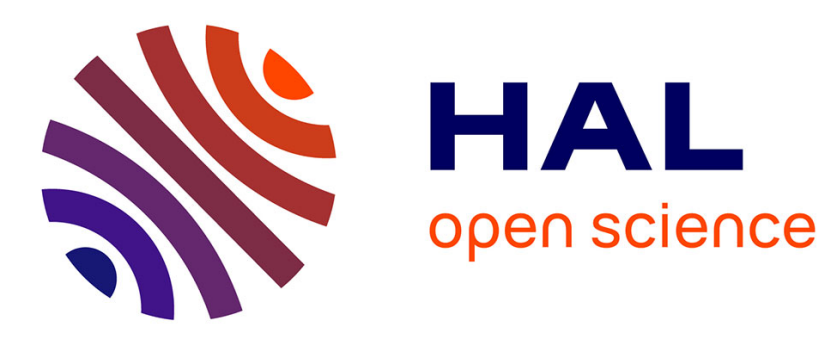

\title{
Data-driven Operation-based Aircraft Design Optimization
}

Dajung Kim, Thierry Druot, Rhea Liem

\section{To cite this version:}

Dajung Kim, Thierry Druot, Rhea Liem. Data-driven Operation-based Aircraft Design Optimization. AIAA AVIATION 2020 FORUM, Jun 2020, (Virtual event ), United States. pp.ISBN: 978-1-62410598-2, 10.2514/6.2020-3156 . hal-02868096

\section{HAL Id: hal-02868096 \\ https://hal-enac.archives-ouvertes.fr/hal-02868096}

Submitted on 25 Jun 2020

HAL is a multi-disciplinary open access archive for the deposit and dissemination of scientific research documents, whether they are published or not. The documents may come from teaching and research institutions in France or abroad, or from public or private research centers.
L'archive ouverte pluridisciplinaire HAL, est destinée au dépôt et à la diffusion de documents scientifiques de niveau recherche, publiés ou non, émanant des établissements d'enseignement et de recherche français ou étrangers, des laboratoires publics ou privés. 


\title{
Data-driven Operation-based Aircraft Design Optimization
}

\author{
Dajung Kim* \\ The Hong Kong University of Science and Technology, Clear Water Bay, Hong Kong \\ Thierry Druot ${ }^{\dagger}$ \\ Ecole Nationale de l'Aviation Civile, Toulouse, France \\ Airbus Operations SAS, Toulouse, France \\ Rhea P. Liem. \\ The Hong Kong University of Science and Technology, Clear Water Bay, Hong Kong
}

\begin{abstract}
In this work, we integrate a mission analysis algorithm into the Multidisciplinary Airplane Research Integrated Library (MARILib), which is a multidisciplinary optimization tool for aircraft sizing. The main purpose of such an integration is to include aircraft operational data from the initial design process, to develop a more realistic aircraft design framework. With this approach, the design and mission requirements that reflect how aircraft actually operate are considered in the design process. Mission analysis tools are developed to model realistic aircraft operations. Data analytics, including clustering algorithms, is performed to extract information from flight data, which then becomes input to MARILib. The aim of the framework is to reduce operational costs of aircraft starting from the initial design itself, by incorporating air transportation data into the conceptual design stages.
\end{abstract}

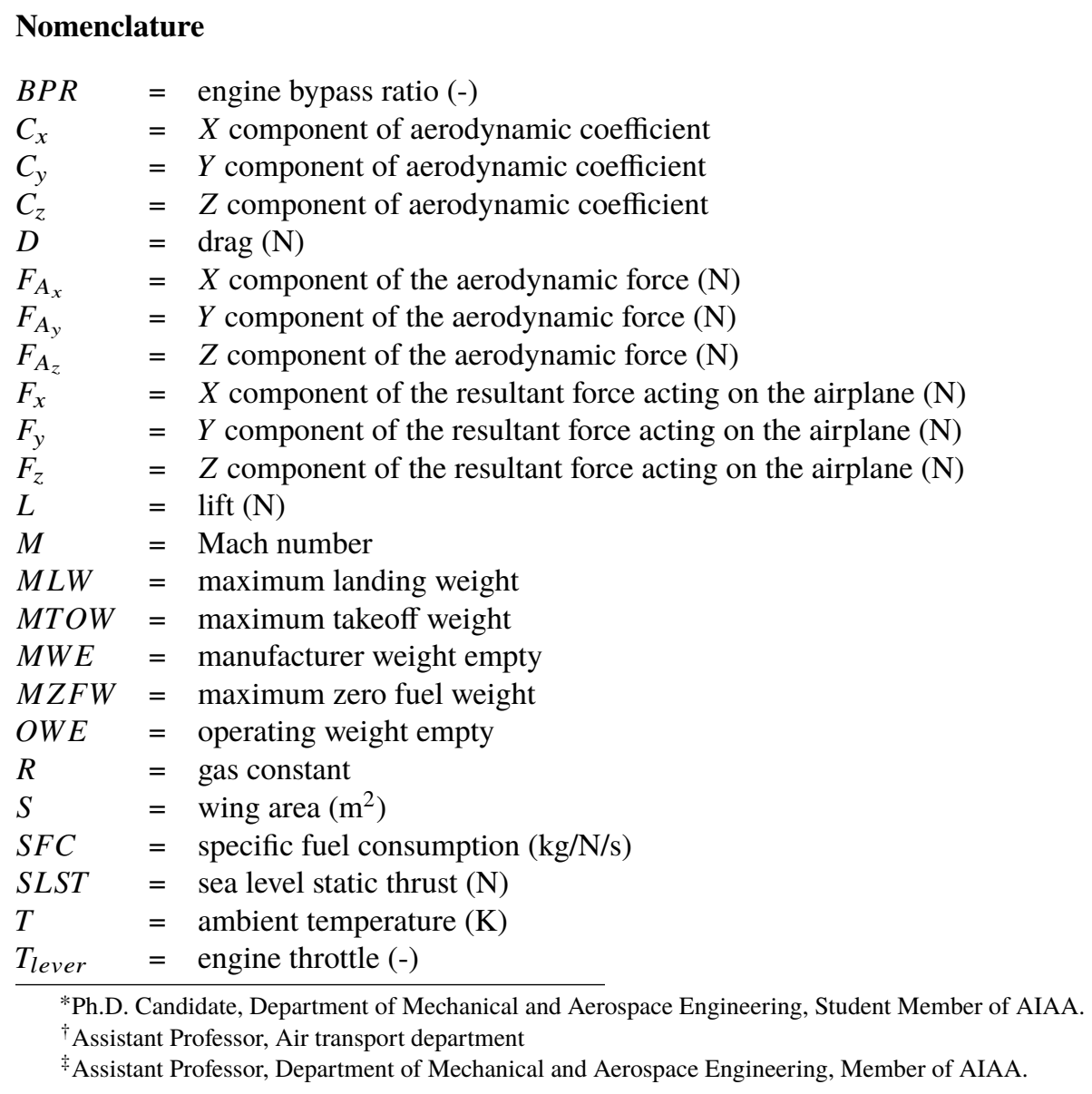




\begin{tabular}{|c|c|c|}
\hline TOW & $=$ & takeoff weight $(\mathrm{N})$ \\
\hline$V_{T A S}$ & $=$ & true air speed $(\mathrm{m} / \mathrm{s})$ \\
\hline$V_{C A S}$ & $=$ & calibrated air speed $(\mathrm{m} / \mathrm{s})$ \\
\hline$a$ & $=$ & speed of sound $(\mathrm{m} / \mathrm{s})$ \\
\hline$d$ & $=$ & distance $(\mathrm{m})$ \\
\hline $\bar{d}$ & $=$ & normalized distance (-) \\
\hline$f_{n}$ & $=$ & thrust per engine $(\mathrm{N})$ \\
\hline$g$ & $=$ & gravitational acceleration $\left(\mathrm{m} / \mathrm{s}^{2}\right)$ \\
\hline$g_{x}$ & $=$ & $X$ component of gravitational acceleration $\left(\mathrm{m} / \mathrm{s}^{2}\right)$ \\
\hline$g_{y}$ & $=$ & $Y$ component of gravitational acceleration $\left(\mathrm{m} / \mathrm{s}^{2}\right)$ \\
\hline$g_{z}$ & $=$ & $Z$ component of gravitational acceleration $\left(\mathrm{m} / \mathrm{s}^{2}\right)$ \\
\hline$m$ & $=$ & $\operatorname{mass}(\mathrm{kg})$ \\
\hline$m_{\text {fuel }}$ & $=$ & fuel mass $(\mathrm{kg})$ \\
\hline$n_{\text {engine }}$ & $=$ & number of engines \\
\hline$p$ & $=$ & rotational velocity with respect to $X$ axis $(\mathrm{rad} / \mathrm{s})$ \\
\hline$q$ & $=$ & rotational velocity with respect to $Y$ axis $(\mathrm{rad} / \mathrm{s})$ \\
\hline$r$ & $=$ & rotational velocity with respect to $Z$ axis ( $\mathrm{rad} / \mathrm{s})$ \\
\hline Range & $=$ & mission range $(\mathrm{m})$ \\
\hline$t$ & $=$ & time $(s)$ \\
\hline $\bar{t}$ & $=$ & normalized time $(-)$ \\
\hline$u$ & $=$ & $X$ component of body frame translational velocity $(\mathrm{m} / \mathrm{s})$ \\
\hline$v$ & $=$ & $Y$ component of body frame translational velocity $(\mathrm{m} / \mathrm{s})$ \\
\hline$w$ & $=$ & $Z$ component of body frame translational velocity $(\mathrm{m} / \mathrm{s})$ \\
\hline$\dot{u}$ & $=$ & $X$ component of body frame translational acceleration $\left(\mathrm{m} / \mathrm{s}^{2}\right)$ \\
\hline$\dot{v}$ & $=$ & $Y$ component of body frame translational acceleration $\left(\mathrm{m} / \mathrm{s}^{2}\right)$ \\
\hline$\dot{w}$ & $=$ & $Z$ component of body frame translational acceleration $\left(\mathrm{m} / \mathrm{s}^{2}\right)$ \\
\hline$x_{E}$ & $=$ & $X$ component of inertial frame position (m) \\
\hline$\dot{x_{E}}$ & $=$ & $X$ component of inertial frame translational velocity $(\mathrm{m} / \mathrm{s})$ \\
\hline$y_{E}$ & $=$ & $Y$ component of inertial frame position $(\mathrm{m})$ \\
\hline$\dot{y_{E}}$ & $=$ & $Y$ component of inertial frame translational velocity $(\mathrm{m} / \mathrm{s})$ \\
\hline$z_{E}$ & $=$ & $Z$ component of inertial frame position $(\mathrm{m})$ \\
\hline$\dot{z_{E}}$ & $=$ & $Z$ component of inertial frame translational velocity $(\mathrm{m} / \mathrm{s})$ \\
\hline$\gamma$ & $=$ & specific heat ratio \\
\hline$\theta$ & $=$ & pitch angle (rad) \\
\hline$\epsilon$ & $=$ & radius \\
\hline$\rho$ & $=$ & air density $\left(\mathrm{kg} / \mathrm{m}^{3}\right)$ \\
\hline$\rho_{0}$ & $=$ & air density at sea level $\left(\mathrm{kg} / \mathrm{m}^{3}\right)$ \\
\hline$\phi$ & $=$ & roll angle (rad) \\
\hline$\psi$ & $=$ & yaw angle (rad) \\
\hline
\end{tabular}

\section{Introduction}

An aircraft design process is typically driven by the specified mission requirements [1]. The top-level aircraft requirements (TLARs) such as mission configuration, payload, cruise speed, etc., are set as constraints in the design optimization problem formulation. Therefore, final design optimization results from an optimization framework are highly dependent on the values of TLARs and proper requirement setting is one of the most critical tasks in aircraft design. TLARs for military aircraft design are primarily decided by the specific mission the aircraft has to achieve. In the case of TLARs for civil aircraft, the aircraft manufacturers set the design requirements by considering future demand, the anticipation of technological development, and applicability of technology. This customary procedure makes it difficult for airlines, the main end users, to actively comment on the design requirements, which creates a gap between air traffic management and aircraft design.

Aircraft systems and air traffic management are highly complex disciplines. Efforts to bridge the two have been underway, though most of them rely on lower-fidelity models at the expense of accuracy. Their interdisciplinary 
coupling, i.e., how they affect each other, however, cannot be overlooked [2]. The increase in air traffic demand over the past two decades has changed many aircraft operations. New routes have been opened due to the construction of new airports or increased demand for air traffic between specific regions. Climate change has also become one of the key considerations in deciding aircraft operating conditions [3]. Our observations on flights around the Hong Kong International Airport (HKIA) show that more and more flights add holding patterns and loiters in their flight mission profiles due to airway congestion, which changes total mission time and will add to fuel consumption and noise impacts [4]. The flight management system (FMS) determines the optimal flight route prior to departure [5]. However, there is still a degree of subjectivity in determination of the actual route. The speed and altitude of stepped climb and cruise segments for the same origin and destination route, for instance, vary depending on the pilot's proficiency or just personal preference. These changes in air traffic management are not currently reflected in aircraft design, but we intuitively know that those have an impact on aircraft performance. If the actual operating point is different from the optimum design point, the aircraft is operating in a manner that consumes more fuel. The aircraft designer cannot change these flight operating conditions and procedures. Instead, we propose a new aircraft design formulation that takes the actual operational data into account as early as the preliminary design stage by changing TLARs.

To fully integrate operational data into the design process, we need to consider its proper performance assessment in the process of aircraft design optimization. The performance assessment here refers to mission analysis to estimate fuel consumption, which affects the direct operating cost. In addition to assessing the cost function, the mission analysis procedure also provides a platform to incorporate operational data. In particular, the flight mission profile can be modeled based on historical flight route data, to reflect the variability in operations. These profiles will also be used to assess the benefits offered by the optimized design, as compared to the actual design. However, even if the input of the mission analysis is changed to the actual operating route, most mission analysis evaluates fuel consumption in two dimensions along the vertical profile. This simplification can result in errors of cost function evaluations, which will reduce the credibility of the results. If it is only a biased error and the design optimization makes relative comparisons, this error is acceptable. However, it can cause a problem when determining the overall size of an airplane in the conceptual design by making the total size larger or smaller. Therefore, it can be more effective to extend the mission analysis by modeling the aircraft's equations of motion in three dimensions. This approach will also assist in modeling actual flight route data directly, since the data are also available in three dimensions.

Due to the discrepancy between the actual flight operating conditions and the optimum design points, the aircraft is generally overdesigned at the expense of efficiency, such as higher fuel consumption than necessary. There is a need for a platform that can simultaneously consider the different flight operation conditions in the design process. Two new procedures will be applied to address these issues. First, we derive realistic design requirements by analyzing actual flight operating data. Second, the conceptual design optimization (airplane sizing) is performed with a time step based mission analysis along an actual operating route obtained from flight data analysis.

This study covers the sizing phase at the aircraft conceptual design stage. In particular, we use flight trajectory database that records information such as flight route (longitude, latitude, and altitude), speed, and attitude information. We assume that uncertainties in weather, air traffic conditions, and pilot's subjectivity are implied in the trajectory database, and these uncertainties are not modeled separately. In Section II] we summarize past efforts to reflect the operational environment in aircraft design and we also discuss about their limitations. Section [IIIdescribes in detail the research methodology used in this study. Section IV presents results and discussion, followed by conclusion.

\section{Literature Review}

Aircraft design and air traffic management influence each other. Acosta et al. [6] described that how operational constraints of air transportation would lead to changes in the aircraft design. More specifically, the Next Generation Air Transportation System (NextGen) improves the airspace network by reducing delay time and improves fuel efficiency along the aircraft's flight path, thus reducing the operating weight of the aircraft. As a result, when aircraft manufacturers design an aircraft for the same number of passengers on the same mission range, they will develop lighter aircraft with smaller fuel capacity and smaller size aircraft, which increase fuel efficiency. Bradley and Droney [7] shows that a combination of air traffic management, aircraft design improvements can reduce fuel burn for a conventional propulsion aircraft up to $18 \%$.

The influence of air traffic management is the consideration of practical aviation operations into the aircraft design process. Multi-point optimization and Multidisciplinary Analysis and Optimization (MDAO) are effective techniques for achieving these goals. 


\section{A. Overview of multi-point optimization}

Unlike single-point optimization which would result in a geometric configuration having the optimal performance at only one flight condition and suboptimal performance at other conditions, multi-point optimization enables the optimum design result to bring out the best performance over multiple flight conditions. Since the actual flight is not under a fixed flight condition, multi-point optimization can better reflect the actual flight situations.

Mark Drela [8] applied single-point and multi-point optimizations for a low Reynolds number airfoil and a transonic airfoil. The study concluded that suitable operating points and weights for variables of the objective function of multi-point optimization were not known a priori. Nemec et al. [9] performed multi-point and multi-objective aerodynamic shape optimizations using a gradient-based Newton-Krylov algorithm. They used the same four Mach numbers conditions as those used in the four-point optimization for the transonic airfoil (RAE 2822) performed by Mark Drela [8]. Leung and Zingg [10] performed medium-fidelity single and multi-point aerodynamic shape optimizations using the Newton-Krylov algorithm. Three operating points of multi-point optimization were selected intuitively, and the weighting was chosen arbitrarily. However, Liem et al. [11-14] proposed new method to select the operating points and the weighting. The method incorporated multi-mission profiles by performing mission analysis, which used surrogate models, under various states within the range-payload envelope. The distribution of flight points along the mission profile was used to minimize drag coefficients in aircraft shape design and to minimize drag and fuel burn in aerostructural design.

\section{B. Overview of multidisciplinary optimization}

Aircraft design is an iterative process evaluating various disciplines, particularly aerodynamics, weight and structures, propulsion, and performance. These disciplines interact with each other and generate coupling effects. Multidisciplinary analysis (MDA) systematically considers these coupling effects in modeling the complex system. Over the past 60 years, research on multidisciplinary analysis has been actively conducted and is expanded to the multidisciplinary design optimization (MDO), which essentially couples MDA with optimization methods [15]. Although the aforementioned typical disciplines in MDA and MDO are already good enough to obtain promising design solutions, here we add flight dynamics as an additional discipline, to consider uncertainties in air traffic management, which are treated as design margins.

As an extension of this, Risse et al. [16] incorporated a prediction and assessment of flying qualities into the preliminary aircraft design process by integrating Preliminary Aircraft Design Suite (PADS), Digital DATCOM ${ }^{*}$, and JSBSim PADS is a multidisciplinary design program developed by the Institute of Aeronautics and Astronautics (ILR) of RWTH Aachen University. Digital DATCOM is a program calculating static stability, aerodynamic forces and control, and dynamic derivative characteristics. JSBSim is an existing 6 degree of freedom flight dynamics model. Schmollgruber et al. [17] [18] also expanded Fixed-wing Aircraft Sizing Tool (FAST), one of the multidisciplinary aircraft analysis and optimization tools developed by ONERA and ISAE-SUPAERO, for air traffic management evaluation by adding JSBSim into FAST. It enabled an aircraft design process to consider flying qualities with stability augmentation system and certification constraints.

\section{Research Methodology}

The sequence of the proposed approach is illustrated in Fig. 1. First, all flight data corresponding to an airport are clustered based on flight range and time, then a cluster is selected based on its dominance. An origin and destination pair (OD pair) which corresponds to a representative point of the selected cluster is chosen. Next, a nominal flight path of the selected OD pair is derived from its flight data. The computed nominal flight path is analyzed to set design requirements and a flight scenario. With all these inputs, we perform a multidisciplinary airplane sizing optimization. The detailed methodology of each step is presented in the following subsections.

\section{A. Selection procedure of a representative original and destination pair using clustering algorithm}

Assuming that the demand and supply of flights are balanced, it will be helpful for airlines if airplane manufacturers identify the flight range and speed with the highest number of flights and set them as design targets. To do so, we first gather flight data from Flightradar24 and obtain the flight range and time information of aircraft departing and landing

\footnotetext{
*http://www.pdas.com/datcom.html

http://jsbsim.sourceforge.net/

https: //www . flightradar24.com/
} 


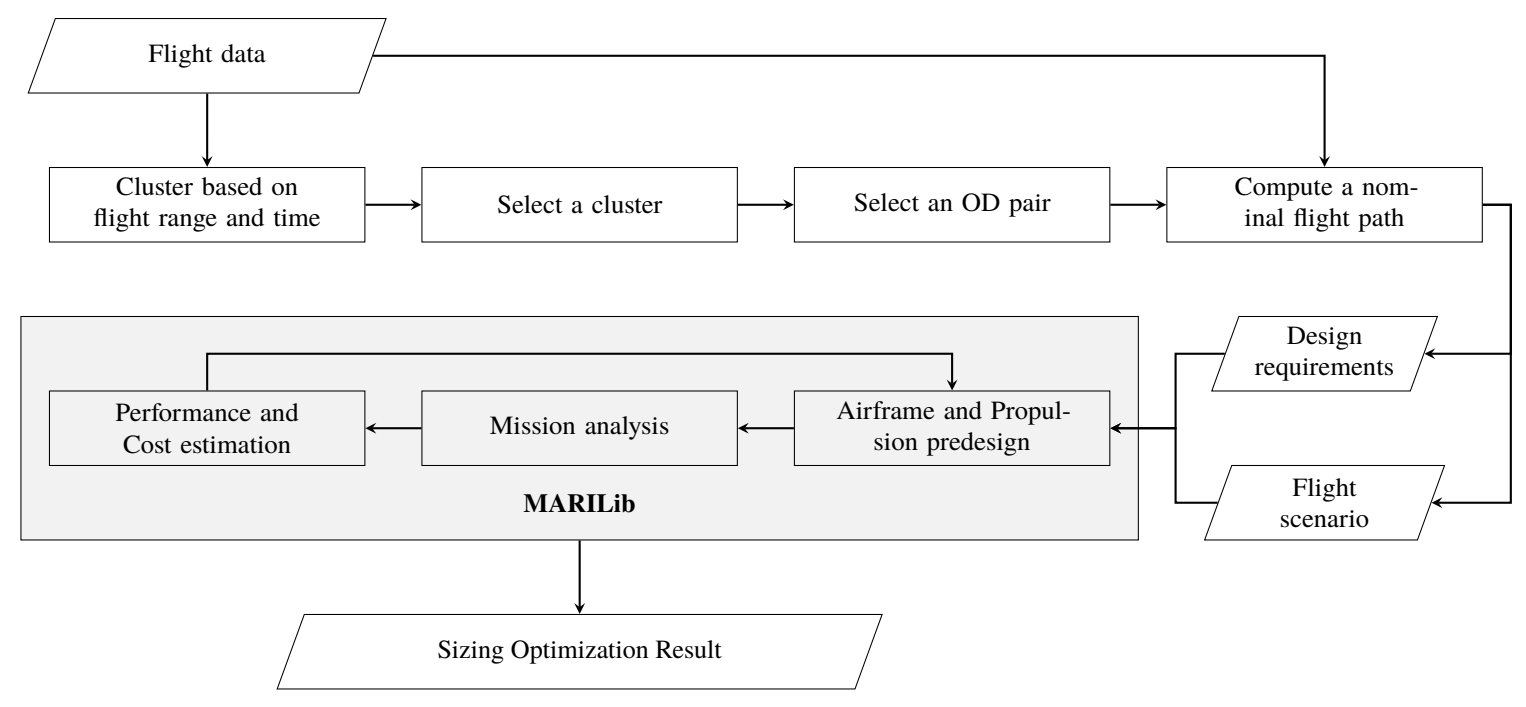

Fig. 1 Flow chart of proposed research

from an airport during a day. The flight data are clustered according to the density of the points plotted on the time and distance axes to consider the current demand of mission range and practical speed. We choose a cluster and select the density center point as the design target point, which corresponds to the highest number of flights in the selected cluster. Next, we find an OD pair of the particular flight time and range that correspond to the design targets of mission range and cruise speed. There are three categories within the clustering algorithm, which is a category of unsupervised machine learning: namely prototype-based, hierarchical, and density-based clustering. Among them, we choose a density-based clustering algorithm to consider the frequency of flight and especially, Density-Based Spatial Clustering of Applications with Noise (DBSCAN) [19] [20] provided by scikit-learn§ is used to exclude flights with unusual behaviour. The number of clusters and core points in DBSCAN is determined by $\epsilon$, the radius of a circle centered in the core point of a cluster, and minimum sample number, the minimum number of points within the circle.

Flight distance and time are calculated from flight data and normalized with respect to their value bounds (minimum and maximum values) as shown in Eq. (1) to remove dimensional dependence. The data are normalized to 1, and the flight time and distance are expressed in coordinates $(\bar{t}, \bar{d})$, where

$$
\bar{t}=\frac{t-t_{\min }}{t_{\max }-t_{\min }}, \quad \bar{d}=\frac{d-d_{\min }}{d_{\max }-d_{\min }} .
$$

\section{B. Proposed method for creating the nominal flight path}

The flight paths can vary for the same OD pair. In order to select our design reference mission profile, we need to find a nominal route which can represent the characteristics of flight routes connecting the same OD pair accurately. The flight data points are arranged chronologically, so even though the sampling rate is the same for all flight data, the average values of latitude, longitude and altitude of the route points of all flight data can result in points through which the airplane does not actually fly. In addition, the average velocity gathered can also cause physical inconsistencies in terms of distance between points and their travel times. We identify the shortest flight time path as reference first. The distance between the waypoints of a reference flight path and the waypoints of other flight path data is calculated. Depending on the this distance, new queues of data points are made for each flight path. The average of them can represent the route that passes through the region where route points are concentrated without physical inconsistencies. Finally, the waypoints of the nominal flight path are the center points with the smallest Euclidean distance to the waypoints of a flight with minimum flight time. For example, the flight points of departing routes having the same OD pair are presented in Fig. 2. Each point represents a waypoint and the waypoints with the same color are on the same flight route. The solid line connecting black points is chosen as the reference route. The distance between black points and other waypoints is computed and the waypoints having the minimum distance are selected and restored in a queue of each flight path. The center point of points in the same index of each queue is the waypoint of nominal route, which is indicated by the circle

$\sqrt[\S]{\text { https://scikit-learn.org/stable/ }}$ 
with a striped pattern. The bold black line represents the flight path chosen as our nominal route. The position, speed,

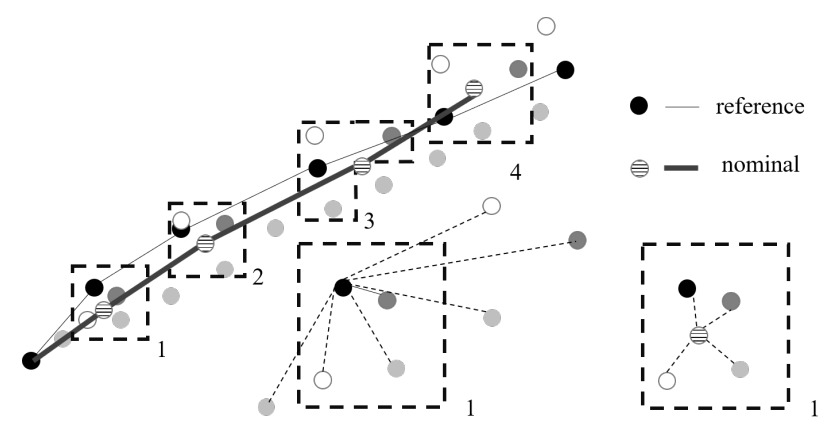

Fig. 2 Explanation of the method for creating nominal route

and attitude angle data of each flight point of the nominal route are used as flight scenarios for mission analysis and TLARs which can reflect multi-mission, multi-flight condition into the optimization. Multi-mission usually refers to the difference in flight conditions and routes of multiple flights due to different payload conditions. However, in this study, it means a difference in routes due to different traffic conditions, and pilots' subjectivity. Multi-flight conditions means the flight conditions at each point of a discretized mission profile for numerical computation.

\section{Airplane design framework}

We use a Python-based multidisciplinary design optimization (MDO) framework called the Multidisciplinary Airplane Research Integrated Library (MARILib] [21] as the design framework. MARILib is developed by a team of researchers from ENAC, Airbus, and IRT Saint Exupery. It is open-source with no closed external dependencies, allowing users to change internal modules. MARILib is well-organized by disciplines, making it easy to understand the overall structure. Users can also separate, add, and modify new modules as needed. The equations used in the framework are mostly based on physical equations with known assumptions, or reproducible statistical regressions of known data or models. In addition, it is designed to be used for a wide range of aircraft, such as super-jumbos or hybrid propulsion systems. The optimization minimizes five criteria such as Maximum Takeoff Weight (MTOW), mission fuel, $\mathrm{CO}_{2}$ emission, cash operating cost, and direct operating cost, with two design variables such as wing area and engine thrust, as shown in Eq. (2). Six parameters in operating performance estimation such as take-off field length, approach speed, time to climb, climb speed at Maximum CRuise (MCR) rating and Maximum CLimb (MCL) rating, and slope of the path at one engine inoperative condition are the constraints.

$$
\begin{array}{ll}
\underset{x=(\mathrm{S}, \mathrm{SLST})}{\operatorname{minimize}} & \text { Criterion }(x) \\
\text { subject to } & g_{i}(x) \leq g_{i}^{\text {constraint }}, i=1, \ldots, 6 .
\end{array}
$$

MARILib's core module chain is summarized in seven steps: initialization, airframe predesign, propulsion predesign, mass and center of gravity estimation, nominal mission simulation, operating performance estimation, and cost estimation. Fig. 3 shows the input and interaction parameters between the seven modules. The parameters in bold in Fig. 3 are newly added for this study.

We especially focus on propulsion predesign, nominal mission simulation, and operating performance modules of MARiLib and improve them. The existing model for calculating specific fuel consumption of turbofan engine is:

$$
S F C=\left(0.4+1 / B P R^{0.895}\right) / 36000 .
$$

As the engine bypass ratio is not included into design optimization, specific fuel consumption is always constant throughout the entire optimization procedure. We replace it with a surrogate model built using flight data fitted using the Regularized Minimal-energy Tensor product Cubic Hermite splines (RMTC) [22] of surrogate modeling toolbox [23]. The specific fuel consumption can vary with altitude, Mach number, and throttle lever setting. The Latin hypercube sampling method is used to select sample data.

$\sqrt[9]{\text { https://github.com/marilib/MARILib }}$ 


\begin{tabular}{|c|c|c|c|c|c|c|c|}
\hline \multirow[t]{2}{*}{ TLARs } & $\begin{array}{l}\text { Propulsion } \\
\text { configuration, } \\
\text { Number of } \\
\text { engines }\end{array}$ & $\begin{array}{c}\text { Cruise Mach, } \\
\text { Number of } \\
\text { passengers }\end{array}$ & $\begin{array}{l}\text { Cruise Mach, } \\
\text { Number of } \\
\text { engines, } \\
\text { Propulsion } \\
\text { configuration }\end{array}$ & $\begin{array}{l}\text { Cruise Mach, } \\
\text { Mission range, } \\
\text { Number of } \\
\text { passengers }\end{array}$ & $\begin{array}{l}\text { Cruise Mach, } \\
\text { Mission range, } \\
\text { Number of } \\
\text { engines, } \\
\text { Propulsion } \\
\text { configuration }\end{array}$ & & \\
\hline & Initialization & $\begin{array}{c}\text { Wing area, } \\
\text { Aspect ratio, } \\
\text { Nacelle y axis, } \\
\text { Nacelle length } \\
\ldots\end{array}$ & $\begin{array}{c}\text { SLST, } \\
\text { Reference cruise } \\
\text { altitude, } \\
\text { BPR, } \\
\text { Engine attachment } \\
\ldots \\
\end{array}$ & $\begin{array}{l}\text { MTOW, } \\
\text { MLW, } \\
\text { MZFW }\end{array}$ & $\begin{array}{c}\text { Payload, } \\
\text { Cruise altitude, } \\
\text { Flight scenario }\end{array}$ & $\begin{array}{c}\text { Operational } \\
\text { requirements, } \\
\text { Flight scenario }\end{array}$ & $\begin{array}{c}\text { Economic } \\
\text { assumptions }\end{array}$ \\
\hline & & $\begin{array}{l}\text { Airframe } \\
\text { predesign }\end{array}$ & $\begin{array}{l}\text { Fuselage width, } \\
\text { Fuselage height, } \\
\text { Fuselage length, } \\
\text { Nacelle x axis }\end{array}$ & $\begin{array}{l}\text { Airframe } \\
\text { geometry }\end{array}$ & $\begin{array}{l}\text { Airframe drag, } \\
\text { Wing area }\end{array}$ & & $\begin{array}{c}\text { Airframe drag, } \\
\text { Airframe lift }\end{array}$ \\
\hline & & $\begin{array}{l}\text { Nacelle y axis, } \\
\text { Nacelle length }\end{array}$ & $\begin{array}{l}\text { Propulsion } \\
\text { predesign }\end{array}$ & $\begin{array}{c}\text { Nacelle mass, } \\
\text { Pylon mass }\end{array}$ & $\begin{array}{l}\text { Engine drag, } \\
\text { Engine thrust, } \\
\text { Engine SFC }\end{array}$ & $\begin{array}{l}\text { Engine drag, } \\
\text { Engine thrust }\end{array}$ & $\begin{array}{l}\text { Engine drag, } \\
\text { Engine thrust, } \\
\text { Engine SFC }\end{array}$ \\
\hline & & & & $\begin{array}{l}\text { Mass and } \\
\text { center of } \\
\text { gravity } \\
\text { estimation }\end{array}$ & $\begin{array}{l}\text { MLW, } \\
\text { OWE, } \\
\text { MZFW }\end{array}$ & $\begin{array}{l}\text { MLW, } \\
\text { OWE }\end{array}$ & $\begin{array}{l}\text { OWE, } \\
\text { MWE }\end{array}$ \\
\hline & & MTOW & & $\begin{array}{l}\text { MTOW, } \\
\text { MLW, } \\
\text { MZFW }\end{array}$ & $\begin{array}{l}\text { Nominal } \\
\text { mission } \\
\text { simulation }\end{array}$ & MTOW & MTOW \\
\hline $\begin{array}{l}\text { Operational } \\
\text { constraints }\end{array}$ & & & & & & $\begin{array}{l}\text { Operating } \\
\text { performance } \\
\text { estimation }\end{array}$ & \\
\hline Criterion & & & & & & & $\begin{array}{c}\text { Cost } \\
\text { estimation }\end{array}$ \\
\hline
\end{tabular}

Fig. 3 N2 diagram of MARILib core modules. The parameters highlighted in bold are newly added for this study. 
The mass computation model of the nominal mission simulation of existing MARILib is shown as:

$$
m_{f u e l}=T O W \times\left(1-\exp \left[\frac{-S F C \times g \times \text { Range }}{V_{T A S} \times(L / D)_{\text {cruise }}}\right]\right) .
$$

The fuel consumption obtained from Eq. (4) is derived under the assumption of cruise condition across the entire flight path. Such a simplification can incur 9 to $36 \%$ of error [24]. By using actual flight data in their study, Yanto and Liem showed that a cruise-only approximation could cause as much as $45 \%$ fuel burn calculation error, with smaller aircraft flying shorter ranges encounter larger error [25]. We improve the mass computation model using a time-stepped flight simulator with fixed waypoints so that the detailed mission is considered to perform flight performance analysis, which will be explained next.

\section{Mission analysis}

Mission analysis narrowly refers to a model for estimating mission range or mission fuel, and broadly refers to a complete set of assumptions related to aircraft operations [26]. Typically, a two-dimensional vertical flight profile is segmented, and flight equilibrium equations are established for each segment. A mission fuel at a fixed mission range or a mission range at a fixed mission fuel is estimated iteratively by solving the equations and a residual equation [27][28]. In this study, we expand it to time-based flight simulation using equations of motionas shown in Fig. 4.

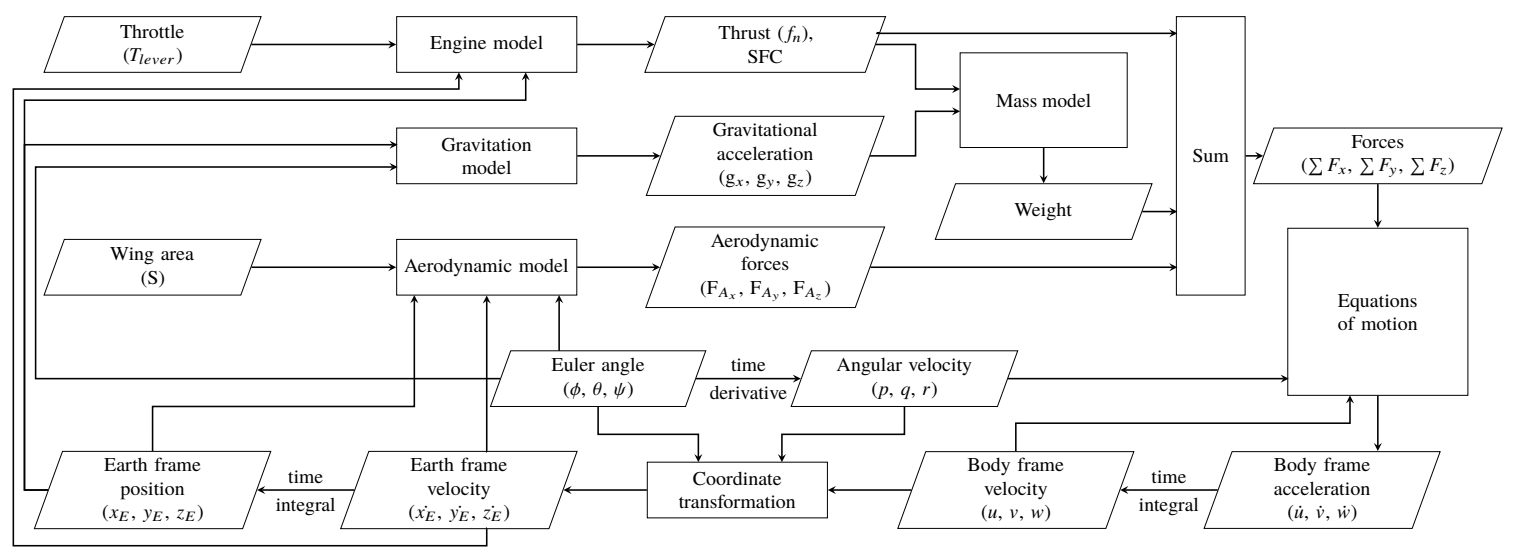

Fig. 4 Data flow and computational procedure of mission analysis

First, we set velocity profile and altitude of each segment of mission derived from flight scenario as inputs. Mission range and cruise Mach number are determined form TLARs. Takeoff weight and wing area are temporary fixed during a loop of design optimization. Engine reference thrust and aerodynamic coefficients are also inputs from the airframe and propulsion predesign modules. then simulation starts with engine model using the initial values of airplane altitude, Mach number and throttle setting for takeoff. Gravitational acceleration varies with the altitude and Euler angles of the airplane, as shown below:

$$
\begin{aligned}
g=g_{0}\left(\frac{R_{E}}{R_{E}+z_{E}}\right)^{2}, \quad & R_{E}=6.356766 \times 10^{6} \mathrm{~m}, g_{0}=9.81 \mathrm{~m} / \mathrm{s}^{2} \\
g_{x} & =-g \sin \theta \\
g_{y} & =g \sin \phi \cos \theta, \\
g_{z} & =g \cos \phi \cos \theta .
\end{aligned}
$$

The airplane mass for next time step is computed using the formula for initial time $t_{i}$ and final time $t_{f}$ equation below:

$$
m_{t_{f}}=m_{t_{i}}-\int_{t_{i}}^{t_{f}} f n \times n_{\text {engine }} \times S F C / g_{z} \mathrm{dt}
$$


The aerodynamic coefficients determined from airframe predesign are used to calculate aerodynamic forces as shown below:

$$
\begin{aligned}
& F_{A_{x}}=1 / 2 \rho V^{2} S C_{x}, \\
& F_{A_{y}}=1 / 2 \rho V^{2} S C_{y}, \\
& F_{A_{z}}=1 / 2 \rho V^{2} S C_{z},
\end{aligned}
$$

where, air density $(\rho)$ is a function of altitude $\left(z_{e}\right)$ from International Standard Atmosphere (ISA) [29]. The resultant forces of each axis is the sum of engine thrust, aerodynamic forces, and weight acting on the each axis.

$$
\begin{aligned}
& \sum F_{x}=f_{n} \times n_{\text {engine }}+m g_{x}+F_{A_{x}} \\
& \sum F_{y}=m g_{y}+F_{A_{y}} \\
& \sum F_{z}=m g_{z}+F_{A_{z}}
\end{aligned}
$$

The resultant moments of each axis are force times moment arm which is the distance between center of gravity and a point of action of force such as aerodynamic center and thrust center. However, we assume that all forces act on the center of gravity for this study. Hence, translational acceleration of body axis can be computed with Eq. (8) and the equations of motion expressed as blow:

$$
\begin{aligned}
& \sum F_{x}=m(\dot{u}+q w-p v), \\
& \sum F_{y}=m(\dot{v}+r u-p w), \\
& \sum F_{z}=m(\dot{w}+p v-q u) .
\end{aligned}
$$

Velocities are calculated from acceleration by integrating the equations of motion transforming to the Earth frame velocity by applying the formula below:

$$
\begin{aligned}
\dot{x_{E}} & =(\cos \theta \cos \psi) u+(\sin \phi \sin \theta \cos \psi-\cos \phi \sin \psi) v+(\cos \phi \sin \theta \cos \psi+\sin \phi \sin \psi) w \\
\dot{y_{E}} & =(\cos \theta \sin \psi) u+(\sin \phi \sin \theta \sin \psi+\cos \phi \cos \psi) v+(\cos \phi \sin \theta \sin \psi-\sin \phi \cos \psi) w \\
\dot{z_{E}} & =-u \sin \theta+(\sin \phi \cos \theta) v+(\cos \phi \cos \theta) w
\end{aligned}
$$

Finally, the position of the airplane relative to the Earth is computed by time integration and used for the input of next time step state variable.

Flight segments consist of takeoff, accelerated climb, constant calibrated airspeed (CAS) climb, constant Mach number climb, constant Mach number cruise, constant Mach number descent, constant CAS descent, and landing. Attitude angles are controlled to meet the velocity requirement of each flight segment. The CAS, which we assume to be the same as equivalent airspeed (EAS), are converted into the corresponding true airspeed (TAS) values by applying Eq. (11):

$$
V_{T A S}=V_{C A S} \cdot\left(\frac{\rho}{\rho_{0}}\right)^{-1 / 2}
$$

where the airport elevation is taken as $0 \mathrm{ft}$ at the mean sea level. While constant Mach number cruise keeps the same true airspeed, the true airspeed decreases at constant Mach number climb according to the relation shown in Eq. (12):

$$
M=\frac{V_{T A S}}{a}, \quad a=\sqrt{\gamma R T} .
$$

In this process, we mainly compute fuel consumption when the airplane flies over a given route following velocity profile and climb and cruise altitude. Mission range requirements can be met by adjusting the length of the cruise segment iteratively. Attitude angles are determined by inner optimization loop depending on the flight segment.

\section{Results and Discussion}

\section{A. Selection procedure of a representative original and destination pair using clustering algorithm}

The 998 flight data of aircraft arriving and departing in Hong Kong International Airport on 5th of February 2018 are gathered and used for the analysis. To run the DBSCAN algorithm, the minimum number of samples is set to be 14 
while $\epsilon$ is equal to 0.06 considering the silhouette coefficient and elbow method. Noisy data, which are considered as outliers, are excluded. Fig. 5 shows the result of DBSCAN clustering algorithm. The result shows three clusters of flight data, each corresponding to a cluster of short, medium, and long-haul flights. The linear trend connecting the cluster centers indicates that all flights have similar speed. For the current study, we focus on group3, which consists of long-haul flights for our study. Although group1 (short-haul flights) seems to dominate the market more with a higher number of flights, the wide spread of points would make it harder to determine the TLARs. To minimize the effect of variation, group3 is selected. Group3 has its density center at $(0.580,0.675)$, which corresponds to 5463 nautical miles (NM) for flight range and 11 hour 20 minutes for flight time after denormalization. Setting Hong Kong as the origin, the OD pair having similar flight range and time as this cluster center is from Hong Kong to London. The flight range from Hong Kong to London is 5209 NM and flight time is 11 hour 51 minutes Therefore, Hong Kong International Airport to London Heathrow is chosen as reference OD pair for creating a nominal route.

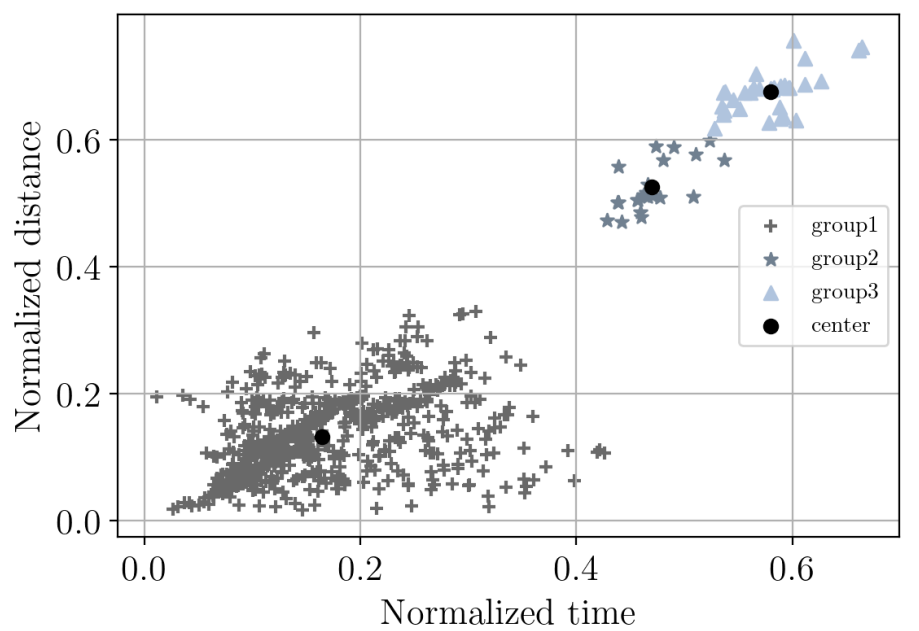

Fig. 5 Clustering results from the DBSCAN algorithm, $\epsilon=0.06$ and the number of minimum samples $=14$.

\section{B. Proposed method for creating the nominal flight path}

The nominal mission scenario is derived based on 130500 flight point of twenty nine actual flight trajectories flying from Hong Kong International Airport (HKIA) to the London Heathrow Airport (LHR). Twenty nine flight data are gathered for a year with at least two flight data gathered for a month, so we can assume that seasonal wind effect on route are implied in the data. The flight trajectories and nominal flight path are illustrated in Fig. 6.

The flight routes analyzed in this study have more than three stepped climb phases above $30000 \mathrm{ft}$. However, the nominal flight path only has a continuous climb phase due to the inconsistency of climb starting points. We segment the flight phases by identifying where the climb and descent rates of the nominal flight path are higher than $10 \mathrm{ft} / \mathrm{s}$ (in either direction) and set a simulation scenario as shown in Table 1, which tabulates the altitude and speed of the different flight phases, from takeoff to landing.

"https://www.airmilescalculator.com/distance/hkg-to-lhr/ 


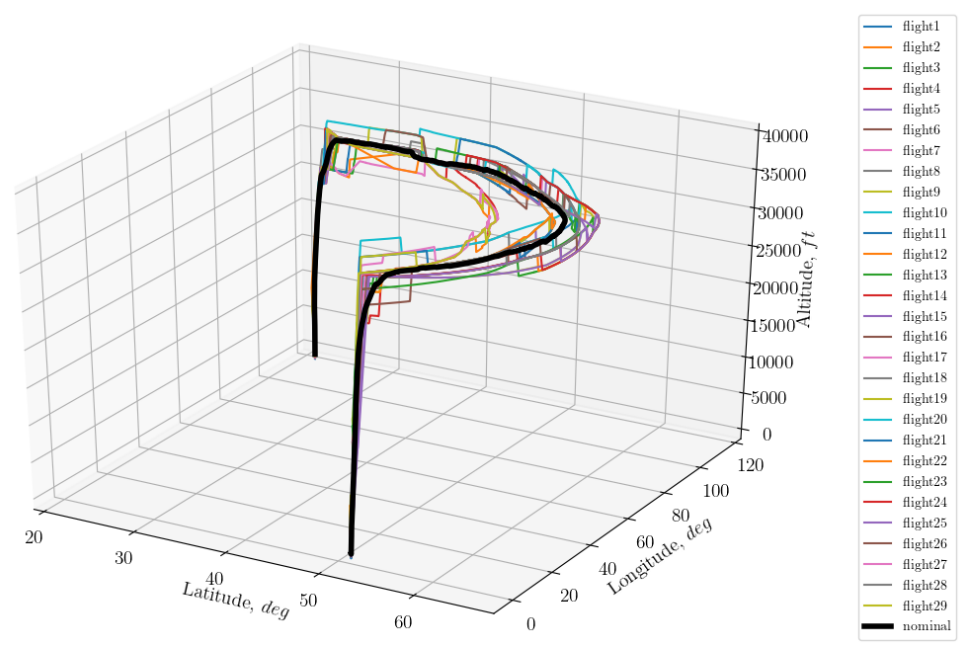

Fig. 6 Reference route for TLARs and flight scenario

Table 1 The flight scenario used in the optimization problem.

\begin{tabular}{cccc}
\hline & Segment & Altitude [ft] & Speed \\
\hline 1 & Takeoff & $0 \rightarrow 1480$ & $0 \rightarrow 390$ KTAS \\
2 & Accelerated climb & $1480 \rightarrow 25260$ & 390 KTAS $\rightarrow 475$ KTAS \\
3 & Constant CAS climb & $25260 \rightarrow 27210$ & 475 KTAS $\rightarrow$ M 0.83 \\
4 & Constant Mach number climb & $27210 \rightarrow 31000$ & M 0.83 \\
5 & Constant Mach number cruise & 31000 & M 0.83 \\
6 & Constant Mach number climb & $31000 \rightarrow 32500$ & M 0.83 \\
7 & Constant Mach number cruise & 32500 & M 0.83 \\
8 & Constant Mach number climb & $32500 \rightarrow 33270$ & M 0.83 \\
9 & Constant Mach number cruise & 33270 & M 0.83 \\
10 & Constant Mach number climb & $33270 \rightarrow 34780$ & M 0.83 \\
11 & Constant Mach number cruise & 34780 & M 0.83 \\
12 & Constant Mach number climb & $34780 \rightarrow 36090$ & M 0.83 \\
13 & Constant Mach number cruise & 36090 & M 0.83 \\
14 & Constant Mach number descent & $36090 \rightarrow 35270$ & M 0.83 \\
15 & Constant CAS descent & $35270 \rightarrow 27560$ & M 0.83 $\rightarrow 478$ KTAS \\
16 & Decelerated descent & $27560 \rightarrow 0$ & 478 KTAS $\rightarrow 80$ KTAS \\
17 & Landing & $0 \rightarrow 0$ & 80 KTAS $\rightarrow 0$ \\
\hline \multicolumn{5}{c}{ Total flight range } & & 5342 NM \\
\hline
\end{tabular}

The speed unit KTAS refers to true airspeed (in knots) and $M$ refers to Mach number. The altitude values of takeoff, accelerated climb, constant CAS climb, and the start point of segment 4, end point of decelerated descent, and landing are not fixed. Instead, it will vary with the force equilibrium, as described in Section III.D to achieve the corresponding speed requirements. However, the angle of attack is set to minimize the altitude error between the reference altitude and corresponding altitude at which the speed requirements are achieved. For example, the altitude of the end point of constant CAS climb is decided by the Mach number setting of segment 4, which is the constant Mach number climb 
segment. The Mach number is set as from the cruise Mach number of TLARs. The aircraft climbs until it reaches the cruise Mach number while maintaining a constant CAS by changing the angle of attack. Fig. 7 shows a velocity profile used in the flight simulation. The numbers in Fig. 7 correspond to the segment number of Table 1 and each vertex refers to the end point of the segment.

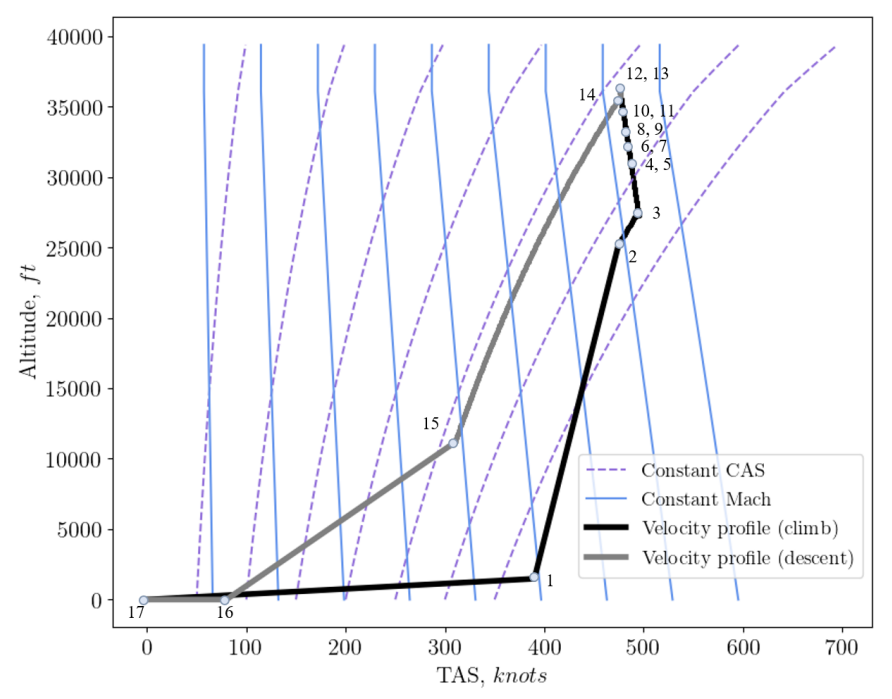

Fig. 7 Velocity profile for the mission analysis

\section{Airplane design framework and mission analysis}

Fig. 8 shows the results from the engine surrogate model of specific fuel consumption (SFC) with different throttle settings, which are used to improve the existing engine module. 3447 points are used for training data and 127053 data points are used for testing the model. The relative error of the model is $7 \%$.
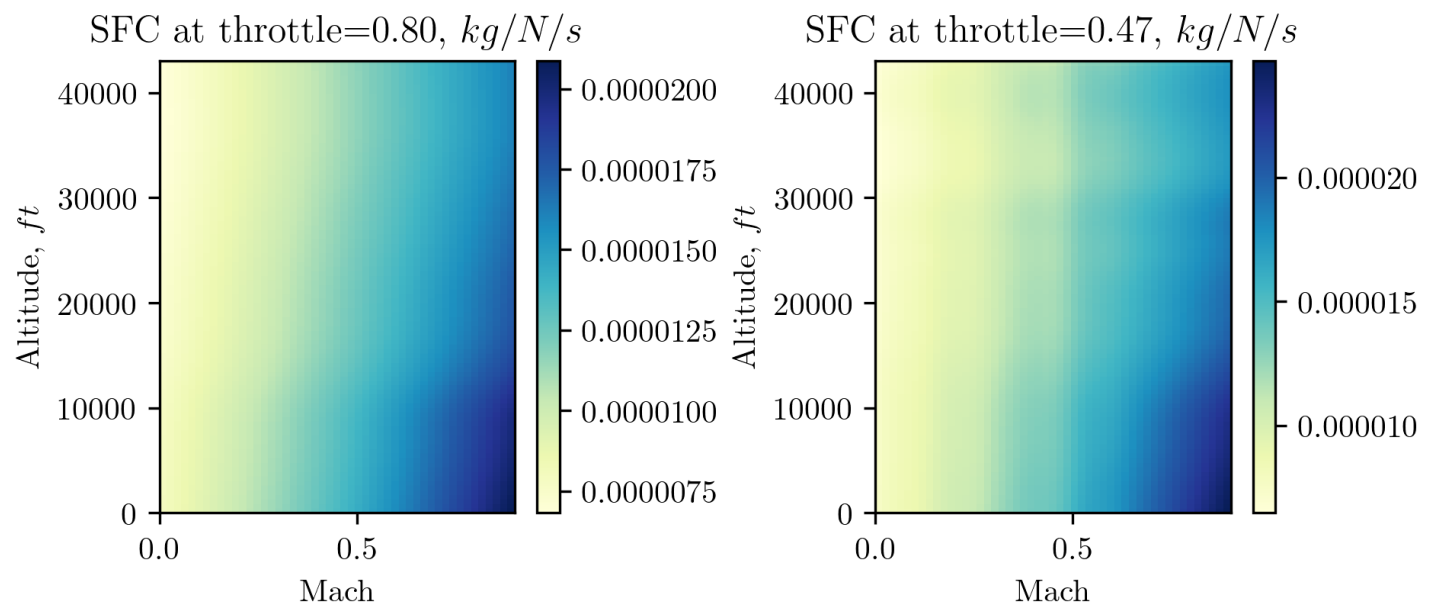

Fig. 8 Specific fuel consumption with respect to Mach number and altitude by RMTC

Table 2 shows the input values including the TLARs. TLARs and reference cruise altitude, reference top of climb altitude are derived from the nominal route. The rest of inputs are referred from the typical airplane flying the selected OD pair. Fig. 9 represents the flight scenario shown in Table 1 and illustrates the definition of design range, reference cruise altitude, and reference top of climb altitude listed in Table 2 Note that this mission analysis profile is not drawn to scale, and is meant mainly for illustration purposes. 


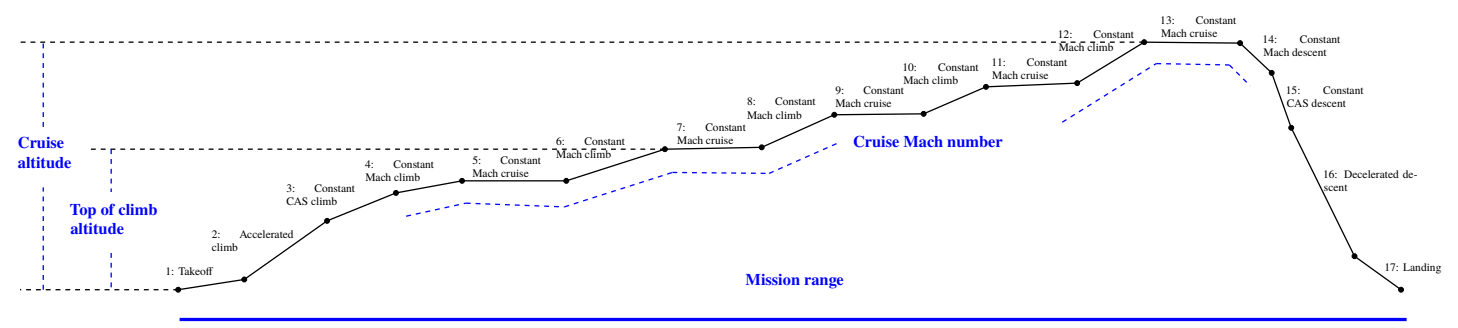

Fig. 9 Mission profile of the flight scenario (not to scale).

Table 2 TLARs and initial settings

\begin{tabular}{ccc}
\hline Input parameter & Value & Unit \\
\hline Propulsion type & Turbofan & \\
Number of engines & 2 & \\
Number of passengers & 350 & \\
Design range & 5340 & $N M$ \\
Cruise Mach number & 0.83 & Mach \\
Reference thrust turbofan & 440000 & $N$ \\
Initial wing area & 440.00 & $\mathrm{~m}^{2}$ \\
Reference cruise altitude & 36090 & $\mathrm{ft}$ \\
Reference top of climb altitude & 31000 & $\mathrm{ft}$ \\
\hline
\end{tabular}

We first validate the derived mission analysis procedure before it is incorporated into MARIlib to assure the accuracy of mass computation during the sizing optimization. To make the mission analysis run independently without connecting it with MARILib, the aerodynamic coefficients and engine thrust which are passed from the original MARILib are replaced with the corresponding surrogate models. The aerodynamic surrogate model is built based on the computational fluid dynamics results of the NASA Common Research Model (CRM) wing calibrated with the wind tunnel test data [30] and Boeing 777-300ER flight data. An engine surrogate model which provides thrust and specific fuel consumption as outputs is formed by the same method explained in Section [III.C. The mass computed from each segment and total fuel consumption from mission analysis and flight data are compared in Table 3 . The flight data for comparison is one of twenty nine flight data which is used to derive nominal route. Mission range requirement is met and the error of total fuel consumption is $0.05 \%$. 
Table 3 The distance of mass comparison for validation of mission analysis

\begin{tabular}{l|rrrrrr}
\hline \multirow{2}{*}{ Segment } & \multicolumn{2}{|c}{ Flight data } & \multicolumn{2}{c}{ Mission analysis } & \multicolumn{2}{c}{ Error } \\
& Distance (NM) & Mass (kg) & Distance (NM) & Mass (kg) & Distance (\%) & Mass (\%) \\
\hline Takeoff & 3.1 & 335951 & 3.0 & 335993 & 2.85 & 0.01 \\
Accelerated climb & 83.6 & 331255 & 84.2 & 331493 & 0.71 & 0.07 \\
Constant Mach number cruise & 128.4 & 330238 & 128.3 & 330567 & 0.04 & 0.10 \\
Constant CAS climb & 137.1 & 329941 & 137.1 & 330269 & 0.01 & 0.10 \\
Constant Mach number cruise & 175.5 & 329113 & 175.1 & 329524 & 0.23 & 0.12 \\
Accelerated climb & 226.6 & 327606 & 223.2 & 328041 & 1.48 & 0.13 \\
Constant Mach number cruise & 1360.4 & 305964 & 1326.4 & 308502 & 2.50 & 0.83 \\
Constant Mach number climb & 1373.3 & 305554 & 1340.1 & 308090 & 2.42 & 0.83 \\
Constant Mach number cruise & 2656.0 & 281929 & 2653.5 & 285579 & 0.09 & 1.29 \\
Constant Mach number climb & 2668.3 & 281584 & 2666.4 & 285219 & 0.07 & 1.29 \\
Constant Mach number cruise & 3986.4 & 258440 & 3987.2 & 260334 & 0.02 & 0.73 \\
Constant Mach number climb & 3998.7 & 258119 & 3999.3 & 259996 & 0.02 & 0.73 \\
Constant Mach number cruise & 5354.0 & 236341 & 5355.7 & 234855 & 0.03 & 0.63 \\
Constant Mach number descent & 5357.6 & 236308 & 5359.3 & 234848 & 0.03 & 0.62 \\
Constant CAS descent & 5445.0 & 235752 & 5448.2 & 234491 & 0.06 & 0.53 \\
Decelerated descent & 5495.4 & 234745 & 5496.3 & 235215 & 0.02 & 0.20 \\
Landing & 5496.7 & 234694 & 5496.7 & 235203 & 0.00 & 0.22 \\
\hline Total fuel consumption & \multicolumn{7}{|c|}{101836.1} & & 101327.3 & & $\mathbf{0 . 0 5}$ \\
\hline
\end{tabular}

Finally, validated mission analysis is connected to design framework and the results of design optimization are represented in Table 4. The results from original MARILib are also presented for comparison purposes. Fig. 10. shows the configuration and sizing resulting from the airplane design optimization proposed in this study.

Table 4 The design optimization result

\begin{tabular}{c|lrrc}
\hline Category & \multicolumn{1}{|c}{ Item } & Original & Updated & Unit \\
\hline \multirow{2}{*}{ Engine } & Reference thrust & 447882 & 506667 & $\mathrm{~N}$ \\
& Bypass ratio & 9 & 9 & - \\
\hline \multirow{2}{*}{ Wing } & Wing area & 431.30 & 454.79 & $\mathrm{~m}^{2}$ \\
& Wing span & 62.30 & 63.98 & $\mathrm{~m}$ \\
\hline \multirow{2}{*}{ Fuselage } & Fuselage length & 66.23 & 66.23 & $\mathrm{~m}$ \\
& Fuselage width & 6.07 & 6.07 & $\mathrm{~m}$ \\
\hline \multirow{5}{*}{ Weight } & MTOW & 269415.53 & 322041.91 & $\mathrm{~kg}$ \\
& MLW & 212428.78 & 223363.54 & $\mathrm{~kg}$ \\
& OWE & 151281.57 & 161500.97 & $\mathrm{~kg}$ \\
& MWE & 131529.59 & 141748.98 & $\mathrm{~kg}$ \\
\hline
\end{tabular}

The fuselage length and width are essentially functions of the number of passengers so the design parameters of the fuselage from the original MARILib and the proposed model are the same. However, the values of reference engine thrust, wing area and span of the proposed model are higher due to the increase in fuel consumption. The original MARILib and proposed model are under the same mission range condition. As the fuel consumption calculated from the applied mission analysis is always higher than the value from the Breguet range which is applied to the original 


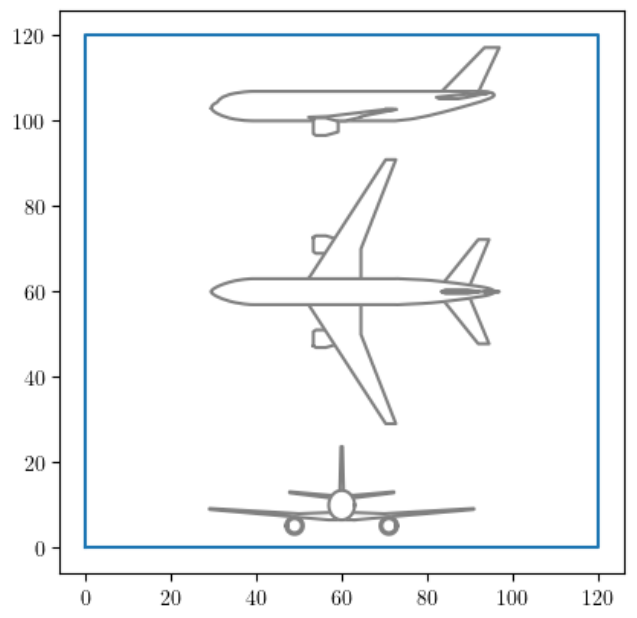

Fig. 10 The drawing results from MARILib.

MARILib, the difference can be either from the accuracy of fuel consumption computation or from the operational consideration of the proposed model.

\section{Conclusion}

A method to incorporate air transportation parameters in the aircraft design optimization is proposed in this study, where TLARs are chosen by analyzing actual operating data. In this work, nominal operating conditions, which can be represented as a flight path and flight speed, are used to assess engine performance, fuel consumption, and flight performance.

The flight data of the aircraft departing and landing for a day are normalized and clustered using the DBSCAN algorithm. The OD pair from HKIA to LHR is selected as the design target path by analyzing the center point of a selected cluster. The nominal flight path is derived from the flight data using the path from HKIA to LHR. The nominal route is applied to the mission analysis as the reference flight path. The inputs of the aircraft design optimization, TLARs, are also decided by the nominal route. The mission analysis which computes the fuel consumption and other performance parameters based on the nominal route, is connected with MARILib, which is an existing aircraft design optimization framework. The proposed mission analysis in this study is a time-based flight simulation, and the equations of motion are solved to determine the flight parameters to follow the velocity profile determined by the nominal route. The mission analysis is validated with the a flight data and the error of fuel consumption is $0.05 \%$, which demonstrates the accuracy of the derived mission analysis procedure. The specific fuel consumption model of the MARILib is also improved to consider the effects of Mach number, altitude, and throttle settings.

The final result of the proposed design optimization framework is the sizing of the airplane. The values of engine reference thrust, optimized wing span and area are higher than the ones from original MARILib. The results show that even for two routes having the same mission range, depending on the operational procedure, and fuel consumption can be different and will contribute to the optimization results of the wing size, engine selection, weight and performance parameters.

An advanced aircraft design framework considering aircraft operational conditions will help design fuel-efficient aircraft and, consequently, contribute to reducing operating cost along with green house gas emissions.

\section{Acknowledgments}

The work was mainly supported by the Hong Kong Research Grant Council Early Career Scheme (Project No. 26202116). Authors would also like to acknowledge The PROCORE-France/Hong Kong Joint Research Scheme 2018/19 (Project No. F-HKUST602/18). Thank you for the generous support. 


\section{References}

[1] Raymer, D., Aircraft design: a conceptual approach, American Institute of Aeronautics and Astronautics, Inc., 2018.

[2] Husemann, M., Schäfer, K., and Stumpf, E., "Flexibility within flight operations as an evaluation criterion for preliminary aircraft design," Journal of Air Transport Management, Vol. 71, 2018, pp. 201-214.

[3] Egelhofer, R., “Aircraft design driven by climate change,” Ph.D. thesis, Technische Universität München, 2008.

[4] Maulydiana, S. F., Guajardo, J. C., and Liem, R. P., "Probabilistic approach in flight trajectory modeling for fast and efficient noise contour generation," Advanced Aircraft Efficiency in a Global Air Transport System, 2018.

[5] Lee, H. P.-c., and Leffler, M., “Development of the L-1011 four-dimensional flight management system,” 1984.

[6] Acosta, D. M., Guynn, M. D., Wahls, R. A., and Del Rosario, R., "Next generation civil transport aircraft design considerations for improving vehicle and system-level efficiency," 2013 Aviation Technology, Integration, and Operations Conference, $2013, \mathrm{p}$. 4286.

[7] Bradley, M. K., and Droney, C. K., "Subsonic ultra green aircraft research,” 2011.

[8] Drela, M., "Pros and cons of airfoil optimization," Frontiers of computational fluid dynamics, Vol. 1998, 1998 , pp. 363-381.

[9] Nemec, M., Zingg, D. W., and Pulliam, T. H., "Multipoint and multi-objective aerodynamic shape optimization," AIAA journal, Vol. 42, No. 6, 2004, pp. 1057-1065.

[10] Leung, T., and Zingg, D., "Single-and multi-point aerodynamic shape optimization using a parallel Newton-Krylov approach," 19th AIAA Computational Fluid Dynamics, 2009, p. 3803.

[11] Liem, R. P., Kenway, G. K., and Martins, J. R., "Multimission aircraft fuel-burn minimization via multipoint aerostructural optimization," AIAA Journal, Vol. 53, No. 1, 2014, pp. 104-122.

[12] Liem, R. P., Mader, C. A., and Martins, J. R., "Surrogate models and mixtures of experts in aerodynamic performance prediction for aircraft mission analysis," Aerospace Science and Technology, Vol. 43, 2015, pp. 126-151.

[13] Liem, R., Kenway, G., and Martins, J., "Multi-point, multi-mission, high-fidelity aerostructural optimization of a long-range aircraft configuration," 12th AIAA Aviation Technology, Integration, and Operations (ATIO) Conference and 14th AIAA/ISSMO Multidisciplinary Analysis and Optimization Conference, 2012, p. 5706.

[14] Liem, R. P., Martins, J. R., and Kenway, G. K., "Expected drag minimization for aerodynamic design optimization based on aircraft operational data," Aerospace Science and Technology, Vol. 63, 2017, pp. 344-362.

[15] Martins, J. R., and Lambe, A. B., "Multidisciplinary design optimization: a survey of architectures," AIAA journal, Vol. 51, No. 9, 2013, pp. 2049-2075.

[16] Risse, K., Anton, E., and Henke, R., "Methodology for flying qualities prediction and assessment in preliminary aircraft design," 10th AIAA Aviation Technology, Integration, and Operations (ATIO) Conference, 2010, p. 9261.

[17] Schmollgruber, P., Bartoli, N., and Gourinat, Y., "Virtual flight testing in an aircraft sizing and optimization process," 15th AIAA Aviation Technology, Integration, and Operations Conference, 2015, p. 2546.

[18] Schmollgruber, P., Bartoli, N., Bedouet, J., Benard, E., and Gourinat, Y., "Improvement of the Aircraft Design process for Air Traffic Management evaluations,” 2018 AIAA Aerospace Sciences Meeting, 2018, p. 0283.

[19] Ester, M., Kriegel, H.-P., Sander, J., Xu, X., et al., "A density-based algorithm for discovering clusters in large spatial databases with noise.” Kdd, Vol. 96, 1996, pp. 226-231.

[20] Schubert, E., Sander, J., Ester, M., Kriegel, H. P., and Xu, X., "DBSCAN revisited, revisited: why and how you should (still) use DBSCAN,” ACM Transactions on Database Systems (TODS), Vol. 42, No. 3, 2017, pp. 1-21.

[21] Druot, T. Y., Belleville, M., Roches, P., Gallard, F., Peteilh, N., and Gazaix, A., "A Multidisciplinary Airplane Research Integrated Library With Applications To Partial Turboelectric Propulsion,” AIAA Aviation 2019 Forum, 2019, p. 3243.

[22] Hwang, J. T., and Martins, J. R., “A fast-prediction surrogate model for large datasets,” Aerospace Science and Technology, Vol. 75, 2018, pp. 74-87. 
[23] Bouhlel, M. A., Hwang, J. T., Bartoli, N., Lafage, R., Morlier, J., and Martins, J. R. R. A., "A Python surrogate modeling framework with derivatives," Advances in Engineering Software, 2019, p. 102662. https://doi.org/https://doi.org/10.1016/j. advengsoft.2019.03.005

[24] Randle, W. E., Hall, C. A., and Vera-Morales, M., "Improved range equation based on aircraft flight data," Journal of Aircraft, Vol. 48, No. 4, 2011, pp. 1291-1298.

[25] Yanto, J., and Liem, R. P., “Aircraft fuel burn performance study: a data-enhanced modeling approach,” Transportation Research Part D: Transport and Environment, Vol. 65, 2018, pp. 574-595. https://doi.org/10.1016/j.trd.2018.09.014

[26] Filippone, A., Advanced aircraft flight performance, Vol. 34, Cambridge University Press, 2012.

[27] Lyu, Y., Yanto, J., and Liem, R. P., "Aircraft Reserve Fuel Study with High-fidelity Fuel Approximation Model,” AIAA Aviation 2019 Forum, 2019, p. 3509.

[28] Kim, D., Lyu, Y., and Liem, R. P., "Flight Profile Optimization for Noise Abatement and Fuel Efficiency during Departure and Arrival of an Aircraft," AIAA Aviation 2019 Forum, 2019, p. 3622.

[29] Atmosphere, S., “ISO 2533: 1975,” International Organization for Standardization, 1975, pp. 11-12.

[30] “NASA Common Research Model,” https://commonresearchmodel.larc.nasa.gov/experimental-data// 2017. 